Ann. Biol. anim. Bioch. Biophys., I969, 9 (2), I7I-Igo.

\title{
ACTION D'UNE CELLULASE FONGIQUE SUR LES MEMBRANES ET SON INTÉRET POUR PRÉVOIR LA DIGESTIBILITÉ DES PLANTES FOURRAGÈRES
}

\author{
R. JARRIGE, P. THIVEND
}

avec la collaboration technique de Marie-Thérèse BEAUfort et Bernadette Bovyon

Station de Recherches sur l'Éler'age des Ruminants, Cientre de Recherches zootechniques et vétérinaires sur les Ruminants, 63 - Theix, près Clermont-Ferrand

Institut national de la Recherche agronomique

\section{SOMMAIRE}

On a étudié l'action d'une préparation cellulasique fongique sur des fourrages d'origine botanique et de digestibilité in vivo très différentes. Elle apparaît comme un mélange d'enzymes qui hydrolyse de façon complète une fraction de la cellulose et des hémicelluloses et attaque aussi les protéines (de l'ordre de $20 \mathrm{p}$. I00). L'importance de la dégradation des polysaccharides membranaires est en corrélation positive avec la digestibilité de ces fractions dans le tube digestif du mouton; elle varie en sens inverse du degré de lignification $(r=-0,87)$; elle est plus élevée pour les graminées que pour les légumineuses de digestibilité comparable. La préparation cellulasique a donc une action relativement semblable à celle de la population microbienne du rumen.

La quantité de substances qu'elle solubilise est en corrélation positive avec la digestibilité du fourrage ; il en est de même pour la quantité de substances extraite par la solution tampon faiblement acide $\left(\mathrm{pH}_{4}, 6\right)$ dans laquelle est diluée la préparation cellulasique et, encore plus, pour la quantité totale de substances extraite lors de la digestion cellulasique : pour les différentes catégories des I29 échantillons étudiés, le coefficient de corrélation est toujours supérieur à 0,80 .

La digestion cellulasique permet de prévoir la digestibilité avec une précision généralement meilleure que les trois autres méthodes auxquelles nous l'avons comparée sur les mêmes échantillons : la cellulose brute Weende, la lignocellulose et la digestibilité in vitro en présence de liquide du rumen. Elle est simple ; elle est aussi reproductible que les méthodes chimiques et, en tout cas, beaucoup plis que la digestibilité in vitro.

\section{INTRODUCTION}

Pour prévoir la valeur nutritive des fourrages, on a proposé de nombreuses méthodes chimiques dont aucune n'est complètement satisfaisante : d'une part, les critères simples tels que la cellulose brute Weende, permettent rarement une estimation précise ; d'autre part, le dosage de la lignine est trop long, surtout s'il est com- 
plété par celui d'autres constituants membranaires. Les méthodes de digestion in vitro du fourrage par du jus de rumen (cf. revue de Johnson, I966), qui ont été proposées au cours des dix dernières années, permettent en général de prévoir la valeur nutritive du fourrage de façon plus satisfaisante que les méthodes chimiques de rapidité comparable. Elles présentent cependant l'inconvénient de nécessiter l'entretien d'animaux porteurs d'une fistule du rumen et d'être, semble-t-il, moins reproductibles que les méthodes chimiques par suite des variations de l'activité microbienne de l'inoculum, tout particulièrement vis-à-vis de la cellulose (cf. BARNES, r967).

Nous avons essayé de supprimer ces inconvénients en remplaçant cet inoculum par une préparation cellulasique, fabriquée industriellement, qui a été étudiée par LE GRAND et Thivend ( 1967 ). Nous avons d'abord précisé la durée optimum de l'attaque du fourrage par cette préparation, la nature et l'importance des produits solubilisés. Nous avons ensuite examiné dans quelle mesure cette attaque présentait une similitude avec celle que subit le fourrage dans le tube digestif des ruminants sous l'action des microorganismes cellulolytiques, et offrait ainsi un moyen de prévoir la digestibilité. Seuls à notre connaissance DoNEFER et al. (1963) ont utilisé une préparation cellulasique dans le même dessein, mais sans en préciser le mode d'action seulement sur un petit nombre (I4) d'échantillons.

\section{MATÉRIEL ET MÉTHODES}

\section{Préparation cellulasique}

La préparation cellulasique utilisée est fabriquée par la S. E. A. B. ('). Elle provient d'une culture d'enrichissement d'un basidiomycète du sol qui n'a pas été identifié.

Elle se présente sous forme d'une poudre blanchâtre, partiellement soluble dans l'eau (60 p. 100); sa teneur en azote (Kjeldahl) varie de 3 à 3,5 p. s.00. La partie soluble renferme la totalité de l'activité cellulolytique laquelle est très stable à $0^{\circ} \mathrm{C}$.

On a préparé la solution cellulasique en centrifugeant une suspension de poudre (1o $\mathrm{mg} / \mathrm{ml}$ ) dans une solution tampon d'acétate de sodium et d'acide acétique à $0,05 \mathrm{M}\left(\mathrm{pH}_{4}, 6\right)$ contenant du nitrure de sodium $(0,05 \mathrm{M})$ comme antiseptique. La solution peut être conservée au froid $\left(+5^{\circ} \mathrm{C}\right)$ pendant environ 24 heures, avant d'être utilisée.

Dans lej conditions fixées ci-après, la solution solubilise en 24 heures 5 p. 100 et 23 p. roo de linters de coton dont les degrés de polymérisation sont respectivement de I 500 et 800.

\section{Méthode}

La digestion cellulasique a lieu (en triple) dans des erlenmeyers de $100 \mathrm{ml}$ placés dans un bainmarie à $40^{\circ} \mathrm{C}$ et soumis à une agitation constante ; des essais préliminaires ont conduit à utiliser $30 \mathrm{ml}$ de la solution cellulasique pour $500 \mathrm{mg}$ de fourrage. A la suite de l'étude cinétique rapportée plus loin, la durée de la digestion a été fixée à 24 heures.

On filtre sur un creuset en verre fritté $n^{0} 2$, préalablement taré, et on lave abondamment à l'eau distillée. Le résidu brut obtenu après dessiccation à l'étuve à $80^{\circ} \mathrm{C}$ est transféré dans une capsule en silice et incinéré à $55^{\circ} \mathrm{C}$ pendant 4 heures.

On a mesuré parallèlement et dans les mêmes conditions, le résidu brut du traitement du fourrage par la solution tampon sans cellulase, (ce résidu retenant la même proportion des cendres du fourrage que le résidu de la digestion cellulasique, nous ne l'avons pas incinéré).

Cela nous permet de faire la part de la solution tampon et de la cellulase dans la digestion cellulasique en distinguant trois extraits :

- l'extrait total par la digestion cellulasique ;

- l'extrait par la solution tampon;

- l'extrait par la cellulase obtenu par différence entre les deux précédents.

(1) S. E. A. B. : Société d'Études et d'Applications Biochimiques (78 - Jouy-en-Josas). 
$\mathrm{Au}$ cours des études, nous avons été amenés à doser les teneurs des différents constituants glucidiques de certains échantillons par la méthode de JARRIGE (196I) qui sépare successivement les glucides solubles, les hémicelluloses, la cellulose et la lignine, et aussi la teneur en lignocellulose (acid detergent fiber) par la méthode d'hydrolyse acide en présence de détergent de VAN SoEST (I963).

\section{Fourrages}

Nous avons choisi les échantillons représentatifs des principales catégories de fourrages. Leur digestibilité avait été mesurée sur des moutons, à un niveau d'ingestion voisin du maximum; leurs teneurs en cellulose brute Weende, matières azotées et cendres avaient été dosées au préalable. De plus, nous avions déterminé la composition glucidique de certains d'entre eux.

Les ray-grass et dactyles ont été choisis parmi les fourrages étudiés par JARRIGE et MINSON (1964) ; leur digestibilité avait été mesurée au Grassland Research Institute de Hurley sur le fourrage congelé après la récolte (MINSON, RAYMOND et HARRIS, 1960). Tous les autres fourrages ont été étudiés à la Station par DEMARQuILLY ; la digestibilité des fourrages verts était mesurée directement sur le fourrage frais coupé chaque matin. Les échantillons de fourrages et de fèces ont été séchés à l'étuve à $80^{\circ} \mathrm{C}$.

\section{RÉSULTATS}

\section{Influence de la durée de digestion}

Nous avons comparé 3 durées de digestion, 6,24 et 48 heures, sur quatre fourrages de nature et de digestibilité (de la matière organique) différentes : deux de foins, un de luzerne (CUD $=56,5$ ) et l'autre de prairie naturelle (CUD $=60,4)$, et deux fourrages dont la digestibilité avait été mesurée à l'état frais : un de luzerne $(\mathrm{CUD}=65,5)$ et 1'autre de fétuque des prés (CUD $=73,9)$. La digestion a été effectuée parallèlement sur le fourrage et sur la lignocellulose correspondante (acid detergent fiber de VAN SoEsT, I963).

Les principaux résultats sont présentés sur la figure I. La quantité de matière sèche extraite du fourrage par la cellulase augmente avec la durée d'une façon curvilinéaire, très comparable pour les quatre échantillons. Rapportée à la valeur 24 heures, elle est en moyenne de 69,3 p. Ioo $(65,7$ à $75, \mathrm{I})$ au bout de 6 heures et de $\operatorname{II} 3,6$ p. roo (I05,o à II9,3) au bout de 48 heures. La quantité extraite de la lignocellulose varie de façon grossièrement parallèle, mais elle est nettement plus faible. Quant à la quantité de matière sèche extraite par la solution tampon, elle n'augmente que très légèrement avec la durée : en valeur relative elle a été de 96,7 , I00 et 103,4 p. Ioo respectivement au bout de 6,24 et 48 heures.

Pour les études ultérieures, nous avons adopté une durée de 24 heures qui représente un compromis commode. En prolongeant au-delà, on accroît peu la quantité de substances solubilisées et on ne modifie pas les différences entre fourrages.

Pour trois des fourrages (le $4^{\mathbf{e}}$ échantillon ayant été égaré), nous avons dosé les hémicelluloses, la cellulose et la lignine brute (JARRIGE, I96r), ainsi que l'azote, après traitement par la solution tampon et après traitement par la solution cellulasique (24 heures). Par différence entre les deux séries de résultats (tabl. I), il apparaît

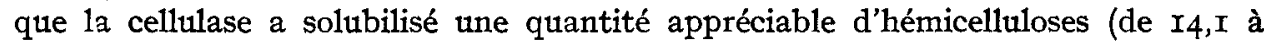
I9,8 p. Ioo du total) qui est même plus élevée que la quantité de cellulose pour deux des trois fourrages. L'hydrolyse a sans doute été complète jusqu'à l'état d'oses puisque l'augmentation des glucides réducteurs de l'extrait correspond sensiblement à la quantité de polysaccharides qui a été solubilisée. La cellulase a également solu- 


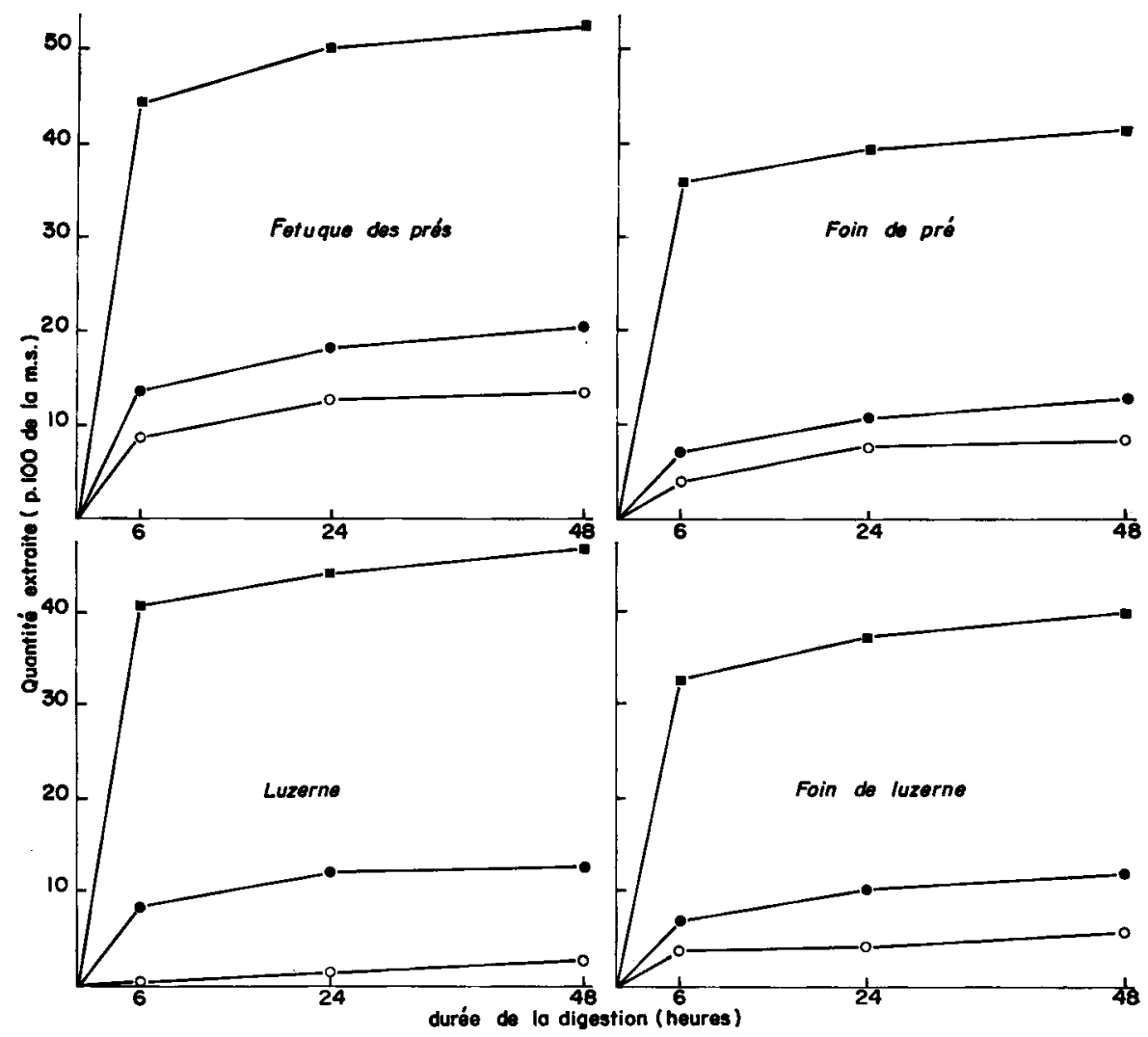

FIG. I. - Influence de la durée de la digesion cellulasique sur le fourrage (extrait total —_- et extrait par la cellulase $-\ldots$ et sur la lignocellulose (extrait total o-- o)

\section{TABLEAU I}

Action comparée du traitement par la solution tampon et par la solution cellulasique (pendant 24 heures)

sur la teneur des constituants membranaires (en pourcentage de la matière sèche du fourrage)

\begin{tabular}{|c|c|c|c|c|c|c|}
\hline & \multicolumn{2}{|c|}{ Fétuque des prés } & \multicolumn{2}{|c|}{ Luzerne } & \multicolumn{2}{|c|}{ Foin de pré } \\
\hline & Tampon & $\begin{array}{c}\text { Tampon } \\
+ \\
\text { cellulase }\end{array}$ & Tampon & $\begin{array}{c}\text { Tampon } \\
+ \\
\text { cellulase }\end{array}$ & Tampon & $\begin{array}{c}\text { Tampon } \\
+ \\
\text { cellulase }\end{array}$ \\
\hline Glucides de l'extrait .......... & 11,1 & 19,6 & 3,8 & 6,4 & 4,7 & 9,8 \\
\hline Hémicelluloses ............ & 17,6 & 14,1 & 11,4 & 10,0 & 17,7 & 15,2 \\
\hline Cellulose $\ldots \ldots \ldots \ldots \ldots \ldots \ldots$ & 22,1 & 16,6 & 16,8 & 15,6 & 23,6 & 21,6 \\
\hline Hémicelluloses + cellulose.... & 39,7 & 30,7 & 28,2 & 25,6 & $\pm 1,3$ & 36,8 \\
\hline Lignine brute . . . . . . . . . & 6,5 & 5,7 & 9,8 & 9,4 & 9,7 & 8,9 \\
\hline Lignocellulose . . . . . . . . . . & 35,9 & 29,3 & 32,9 & 30,7 & 39,5 & 36,2 \\
\hline
\end{tabular}


bilisé une proportion importante des matières azotées (de 20,3 à 23,I p. roo) et diminué la teneur en lignine brute (de 8 , I à $\mathrm{I} 2,3 \mathrm{p}$. IOO). La somme des quantités d'hémicelluloses, cellulose, lignine et matières azotées solubilisées rend compte de la quasi-totalité de la matière sèche extraite par la cellulase pour la fétuque et le foin $(94,9$ et 95,3 p. Ioo respectivement) ; elle lui est supérieure (III,8 p. I00) pour la luzerne, sans doute parce que le facteur de conversion 6,25 est trop élevé pour les constituants azotés solubles qui sont très abondants dans cette plante.

La préparation cellulasique utilisée est donc très impure et contient, en plus des cellulases, des enzymes capables d'hydrolyser certaines fractions des hémicelluloses et des enzymes protéolytiques.

\section{Variations des quantités des substances extraites par la cellulase}

Nous avons analysé les variations des quantités de cellulose et d'autres substances solubilisées par la cellulase pendant 24 heures sur 17 échantillons de fourrages (tab1. 2) dont la digestibilité (de la matière organique) variait de 49,4 à 80,9 . Nous avons estimé :

- la cellulose solubilisée, par différence entre les lignocelluloses obtenues direc-

TABLEAU 2

Variations des quantités de substances extraites par la digestion cellulasique (24 heures)

\begin{tabular}{|c|c|c|c|c|c|c|}
\hline & \multirow{3}{*}{ Cycle } & \multirow{3}{*}{$\begin{array}{l}\text { Digestibilité } \\
\text { de la matière } \\
\text { organique }\end{array}$} & \multicolumn{4}{|c|}{$\begin{array}{l}\text { Substances extraites par la cellulase } \\
\text { (p. } 100 \text { de la matière sèche du fourrage) }\end{array}$} \\
\hline & & & \multicolumn{3}{|c|}{ Sur le fourrage } & \multirow{2}{*}{$\begin{array}{l}\text { Sur la } \\
\text { lignocellulose }\end{array}$} \\
\hline & & & Total & Cellulose & $\begin{array}{c}\text { Autres } \\
\text { substances }\end{array}$ & \\
\hline \multirow{8}{*}{ Foins de prairie } & 1 & 66,2 & 9,5 & 5,4 & 4,1 & 13,2 \\
\hline & 1 & 62,8 & 7,6 & 1,0 & 6,6 & 7,4 \\
\hline & 1 & 60,5 & 9,8 & 4,2 & 5,6 & 11,6 \\
\hline & 1 & 57,2 & 7,0 & 2,6 & 4,4 & 13,3 \\
\hline & 1 & 53,5 & 9,0 & 3,7 & 5,3 & 11,8 \\
\hline & 1 & 49,4 & 6,1 & 3,1 & 3,0 & 10,4 \\
\hline & 1 & 80,9 & 11,7 & 0,5 & 11,2 & 6,9 \\
\hline & 1 & 75,7 & 11,3 & 1,3 & 10,0 & 7,0 \\
\hline \multirow[t]{3}{*}{ Luzerne } & 1 & 70,8 & 8,5 & 2,8 & 5,7 & 7,0 \\
\hline & 2 & 65,4 & 8,0 & 1,6 & 6,4 & 4,1 \\
\hline & 2 & 63,0 & 8,5 & 3,9 & 4,6 & 4,9 \\
\hline \multirow{3}{*}{ Ray-grass anglais } & 1 & 80,0 & 22,6 & 9,6 & 13,0 & 12,8 \\
\hline & 3 & 74,4 & 15,0 & 6,7 & 8,3 & 11,8 \\
\hline & 1 & 66,7 & 12,6 & 6,5 & 6,1 & 10,7 \\
\hline \multirow{3}{*}{ Dactyle } & 1 & 78,2 & 20,2 & 8,8 & 11,4 & 13,2 \\
\hline & 1 & 65,6 & 13,5 & 7,7 & 5,8 & 13,1 \\
\hline & 1 & 55,7 & 11,1 & 5,8 & 5,3 & 9,9 \\
\hline
\end{tabular}


tement et après traitement du fourrage (cette estimation n'est cependant pas rigoureuse car la lignocellulose de VAN SOEST contient des résidus d'hémicelluloses) ;

- les autres substances solubilisées, en soustrayant la cellulose solubilisée de la matière sèche extraite du fourrage par la cellulase.

Nous avons parallèlement soumis les lignocelluloses de ces fourrages à la digestion cellulasique pendant 24 heures.

Les quantités solubilisées, rapportées à la matière sèche du fourrage, sont très variables (tabl. 2) : de 0,5 à 9,6 p. Ioo pour la cellulose, de 3,0 à 13,0 pour les autres substances et de 6,I à 22,6 pour l'extrait total. La quantité de cellulose extraite augmente sensiblement avec la digestibilité du fourrage pour les graminées et les foins mais non pour la luzerne. Elle est beaucoup plus faible pour la luzerne que pour les graminées de digestibilité comparable; on retrouve la même différence pour la cellulose extraite de la lignocellulose ; il est à noter que l'échantillon de foin qui se comporte comme la luzerne se trouve être à base de sainfoin. La cellulose des légumineuses est donc plus résistante à la digestion cellulasique que celle des graminées. Ia quantité de substances autres que la cellulose qui sont extraites par la cellulase (tabl. 2) varie dans le même sens que la digestibilité, sans marquer de différence entre les types de fourrages. Il en est de même pour la quantité totale extraite, mais elle est plus élevée pour les graminées que pour les légumineuses et les foins, faits qui seront confirmés plus loin sur un plus grand nombre d'échantillons (fig. 5, tabl. 3).
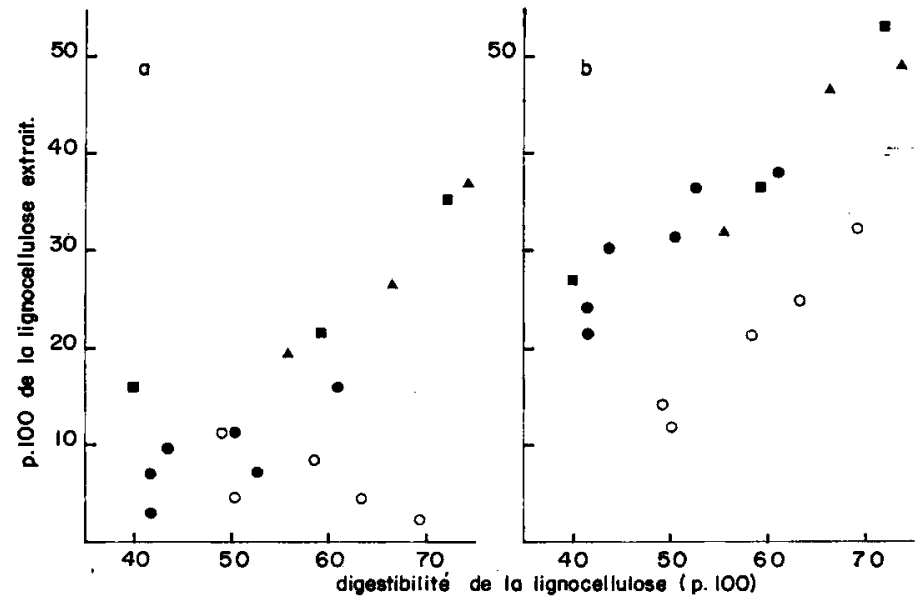

FIG. 2. - Relation entre le pourcentage de la lignocellulose qui est extraite par la cellulase, dans le fourrage (a) el dans la lignocellulose isolée (b), et la digestibilité de la lignocellulose o Luzerne A ray-grass anglais - dactyle - foins de pré

Pour comparer l'action de la cellulase à celle des microorganismes du tube digestif sur les I7 échantillons précédents, nous avons mis en parallèle la proportion de la lignocellulose qui est extraite par la cellulase, soit du fourrage (fig. 2 a), soit de la lignocellulose isolée, avec la digestibilité de la lignocellulose in vivo (fig. $2 b$ ). Nous obtenons des liaisons positives significatives dans les deux cas pour les I2 échantillons de graminées et de foins $(r=0,89$ et 0,95 respectivement) et dans le deuxième cas pour les 5 échantillons de luzerne $(r=0,98)$.

Dans le même dessein, nous avons soumis à la digestion cellulasique un certain 
nombre d'autres échantillons dont nous connaissions les teneurs en hémicelluloses, cellulose et lignine, ainsi que la digestibilité de ces fractions. Pour cet ensemble de 34 échantillons (I2 graminées, I4 légumineuses et 8 foins à flore complexe), l'extrait par la cellulase présente une liaison positive avec les polysaccharides membranaires digestibles $(r=0,7 \mathrm{I}$, fig. $3 b$ ), les deux variables étant exprimées en pourcentage de la matière sèche du fourrage. Exprimé en pourcentage des polysaccharides membranaires (dont il provient essentiellement), l'extrait par la cellulase est en liaison encore plus étroite $(r=0,88$, fig. $3 a$ ) avec la digestibilité de ces polysaccharides et il varie en sens inverse de la teneur en lignine brute $(r=-o, 87)$.
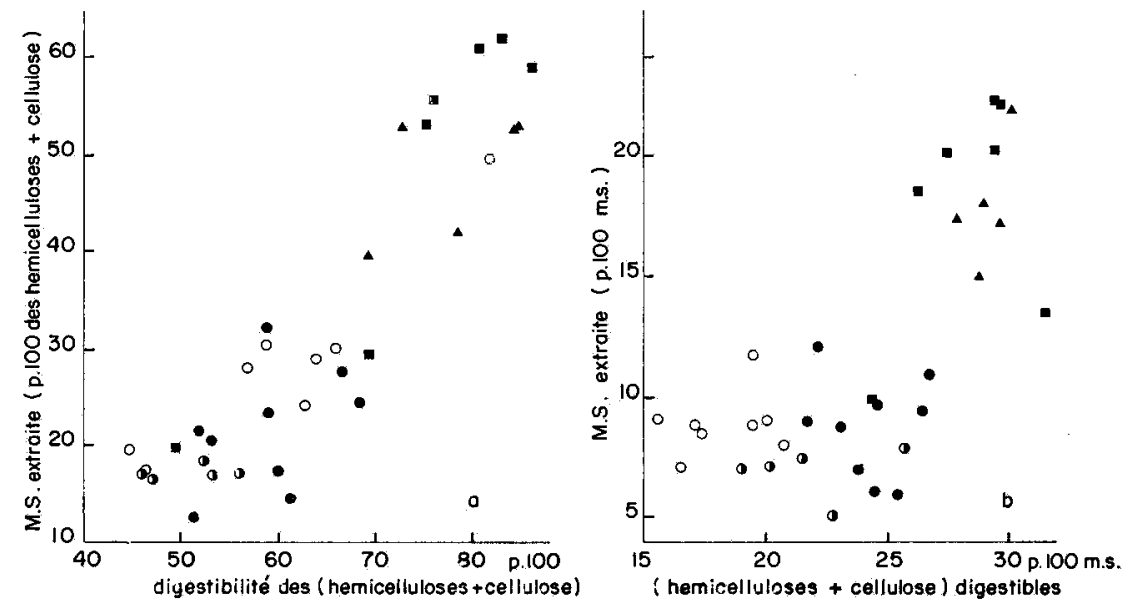

FIG. 3.

(a) Relations entre la matière sèche extraite par la cellublase et la digestibilité des polysaccharides membranaires, hémicelluloses + cellulose (la matière extraite est exprimée en pourcentage dés polysaccharides).

(b) Relation entre la matiere seche extraite par la cellulase et les polysaccharides membranaires digestibles (les deux variables sont exprimées en pourcentage de la matière sèche du fourrage).

- ray-grass anglais : dactyle $\circ$ Luzerne foins de luzerne foins de prairies nuturelles

De ces diverses comparaisons ressort une similitude dans l'action sur les membranes des plantes fourragères entre la cellulase fongique et les enzymes microbiens du tube digestif des ruminants, essentiellement ceux des bactéries cellulolytiques du rumen.

\section{Relation avec la digestibilité du fourrage}

La digestibilité de la matière organique est en étroite corrélation négative avec les résidus des trois traitements effectués sur les 17 fourrages du tableau 2 dans l'étude précédente: (I) digestion cellulasique du fourrage pendant 24 heures $(r=-0,944)$, (2) dosage de la lignocellulose sur le résidu de cette digestion $(r=-0,901)$ et (3) digestion cellulasique pendant 24 heures de la lignocellulose préalablement isolée $\mathrm{du}$ fourrage $(r=-0,823)$. La simple digestion cellulasique du fourrage apparaît donc comme le plus intéressant des trois traitements pour prévoir la digestibilité ; c'est aussi de beaucoup le plus rapide.

Nous avons donc appliqué cette digestion cellulasique pendant 24 heures à II6 autres fourrages dont la digestibilité avait été mesurée sur des moutons. Nous les avons choisis de façon à constituer un échantillon satisfaisant (tab1, 3) de gra- 


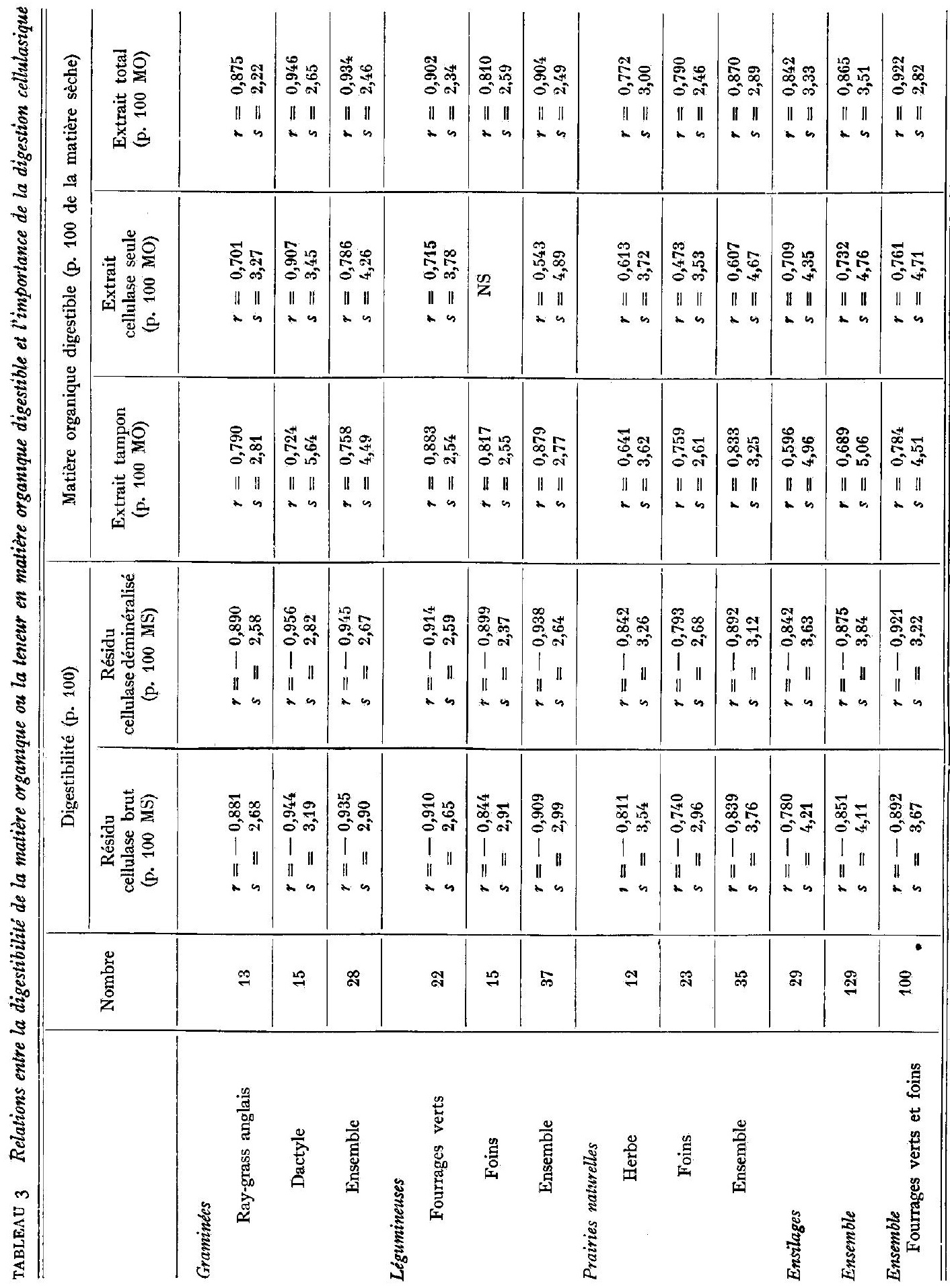


minées pures, ray-grass anglais et dactyle, de légumineuses, luzerne et trètle violet distribués verts ou sous forme de foin, d'herbe et de foins de prairie naturelle et d'ensilages (essentiellement des ensilages de graminées conservés par différentes méthodes : préfanage, acides, mélasse...) ; les coefficients de digestibilité varient au total de 49,4 à 83,2 p. Ioo et les figures 7 à Io en montrent, chacune, les limites de variation pour chaque groupe d'échantillons. Nous avons dosé le résidu de la digestion cellulasique et le résidu du traitement par la solution tampon; nous en avons déduit l'extrait total, l'extrait par la solution tampon, et l'extrait par la cellulase, extraits que nous avons exprimés en pourcentage de la matière organique du fourrage. Au vu des résultats, nous avons éliminé quatre échantillons atypiques : un d'herbe de prairie naturelle et trois de ray-grass qui étaient très riches en glucides solubles.

Nous avons mis en relation, d'une part les extraits avec la proportion de matière organique digestible dans la matière sèche et d'autre part, les résidus avec le coefficient de digestibilité de la matière organique.

L'amplitude de variation des différents critères est considérable : ro,2 à 38,8 p. Ioo de la matière organique pour l'extrait par la solution tampon (fig. 4), 6,2 à

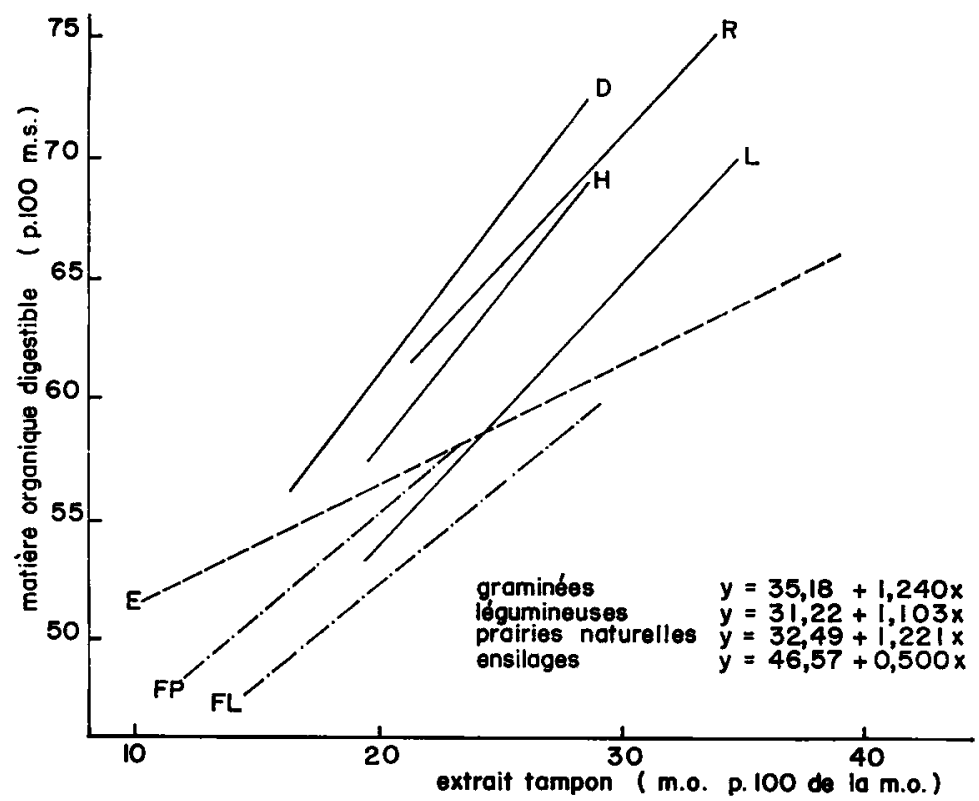

FIG. 4. - Relations entre la matiere organique digestible et la proportion de la matière organique extraite par la solution tampon ( $\mathrm{R}=$ ray-grass ; $\mathrm{D}=$ dactyle $\mathrm{L}=$ fourrages verts de légumineuses $\mathrm{FL}=$ foins de légumineuses ; $\mathrm{H}=$ herbe de prairie naturelle $\mathrm{FP}=$ foins de prairies naturelles ; $\mathrm{E}=$ ensilages)

28,6 p. Ioo pour l'extrait par la cellulase seule (fig. 5), I8,9 à 6I,3 p. Ioo pour l'extrait total (fig. 6), 35,3 à 73,0 p. Ioo de la matière sèche pour le résidu déminéralisé de la digestion cellulasique (fig. 7). L'extrait par la cellulase seule est à nouveau beaucoup plus élevé, et plus variable, pour les graminées que pour les légumineuses de digestibilité comparable (fig. 5). 


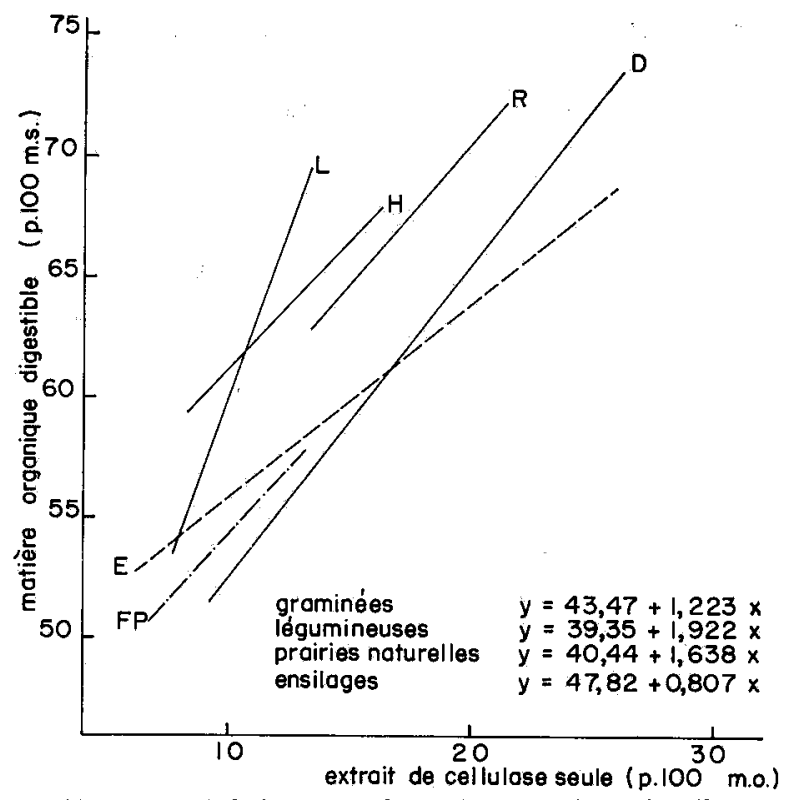

FIG. 5. - Relations entre la matière organique digestible

et la proportion de la matière organique extraite par la cellulase

$(R=$ ray-grass ; $\mathbf{D}=$ dactyle $; L=$ fourrages verts de légumineuses

$\mathrm{H}=$ herbe de prairie naturelle; $\mathrm{FP}=$ foins de prairies naturelles; $\mathrm{E}=$ ensilages)

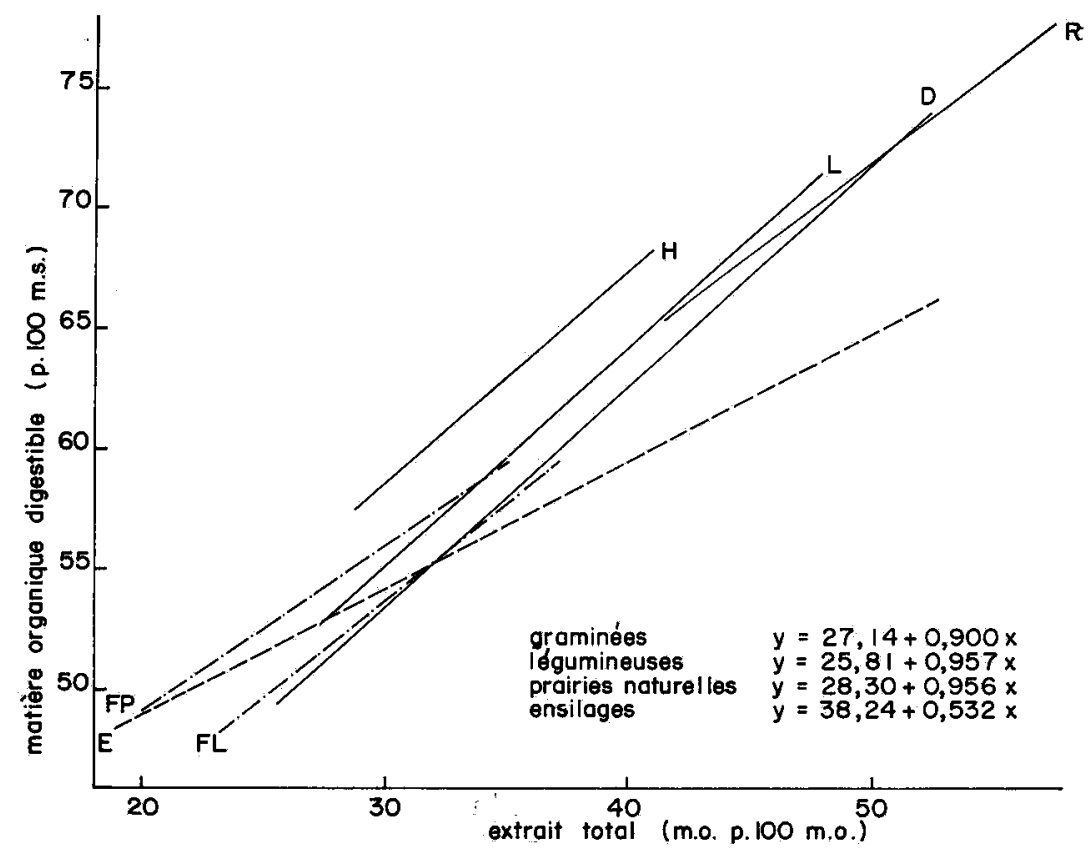

Fig. 6. - Relations entre la matière organique digestible

et la proportion de la matière organique extraite par la digestion cellulasique

$(R=$ ray-grass ; $D=$ dactyle ; $L=$ fourrages verts de légumineuses ;

$\mathrm{FL}=$ foins de légumineuses $; \mathrm{H}=$ herbe de prairie naturelle;

$\mathrm{FP}=$ foins de prairies naturelles; $\mathrm{E}=$ ensilages) 
La matière organique digestible présente une corrélation positive avec les différents extraits et pour chaque catégorie de fourrages (tabl. 3), mis à part l'extrait par la cellulase seule dans le cas des foins de légumineuses. C'est avec l'extrait total que la relation est la plus étroite ; la matière organique digestible peut en être déduite avec une erreur moyenne (écart-type réduit) inférieure à 3 points (tabl. 3), excepté pour l'herbe de prairie naturelle et les ensilages ; les droites de régression des différentes catégories sont relativement voisines et parallèles (fig. 6). Voici les relations linéaires entre la teneur en matière organique digestible $(y)$ et l'extrait total $(x)$ d'une part, pour l'ensemble des I29 échantillons, et d'autre part, pour les roo échantillons de fourrages verts et de foins :

$$
\begin{aligned}
& n=\mathrm{I} 29 ; y=34,35+0,702 x( \pm 3,5 \mathrm{I}) \\
& n=\text { I00 } ; y=30,52+0,836 x( \pm 2,82)
\end{aligned}
$$

La digestibilité de la matière organique est en corrélation inverse étroite avec le résidu de la digestion cellulasique brut ou déminéralisé (tab1. 3, fig. 7) pour chaque catégorie d'échantillons. Les droites de régression sont relativement parallèles et voisines (fig. 7) à l'exception de celle des ensilages. Les relations entre la digestibilité $(y)$ et le résidu déminéralisé $(x)$ pour les ensembles de I29 et de roo échantillons sont les suivantes :

$$
\begin{aligned}
& n=\mathrm{I} 29 ; y=\mathrm{II} 6,2 \mathrm{x}-\mathrm{0}, 869 x( \pm 3,84) \\
& n=\mathrm{I00} ; y=\mathrm{I} 26,96-\mathrm{I}, 035 x( \pm 3,22)
\end{aligned}
$$

Dans aucun des cas, l'ajustement à une relation du $2^{\mathbf{e}}$ degré, n'augmente la valeur du coefficient de corrélation.

Nous avons comparé ces relations à celles observées sur les mêmes échantillons entre la digestibilité de la matière organique d'une part, et les teneurs en cellulose brute Weende et lignocellulose (acid detergent fiber de VAN SoEST, I963) d'autre part, ainsi qu'avec la digestibilité in vitro mesurée selon la méthode de TIILEY et TERRY (I963) ; ces deux dernières mesures n'ont malheureusement pas pu être effectuées sur tous les échantillons. Les coefficients de corrélation et les écarts-types réduits sont rassemblés au tableau 4; les figures 7 à ro présentent les droites de régression par catégories de fourrages et les équations de régression par groupes (graminées, légumineuses, prairies naturelles, ensilages) et illustrent l'amplitude de variation. La relation est plus étroite avec le résidu de la digestion cellulasique qu'avec les teneurs en cellulose brute ou lignocellulose pour les différentes catégories de fourrages, sauf pour les foins de prairie naturelle (ainsi que pour les ray-grass dans le cas de la cellulose brute). On retrouve la même différence pour l'ensemble des 88 échantillons de fourrages verts et foins (en dehors des ensilages) sur lesquels porte la comparaison : les écarts-types réduits sont 3,34, 3,87 et 4,I4 respectivement pour le résidu de la digestion cellulasique, la lignocellulose et la cellulose brute et se classent en sens inverse de l'amplitude de variation (comparer les figures 7,8 et 9).

Le résidu de la digestion cellulasique présente également une liaison plus étroite avec la digestibilité in vivo que ne le fait la digestibilité in vitro mesurée suivant la méthode de TIILEY et TERRY pour trois des quatre catégories de fourrages sur lesquelles porte la comparaison (tabl. 4, fig. Io) : légumineuses (fourrages verts et foins), herbe de prairie naturelle et ensilage. La digestibilité in vitro a l'inconvénient de donner des valeurs beaucoup plus élevées pour les foins que pour les fourrages 
TABLEAU 4

Relations comparées entre la digestibilité de la matière organique et différents critères

\begin{tabular}{|c|c|c|c|c|c|}
\hline & Nombre & $\begin{array}{l}\text { Résidu cellulase } \\
\text { (p. } 100 \mathrm{MS} \text { ) }\end{array}$ & $\begin{array}{l}\text { Digestibilité } \\
\text { in vitro } \\
\text { (p. 100) }\end{array}$ & $\begin{array}{c}\text { Cellulose brute } \\
\text { Weende } \\
\text { (p. } 100 \mathrm{MS})\end{array}$ & $\begin{array}{l}\text { Lignocellulose } \\
\text { (p. } 100 \text { MS) }\end{array}$ \\
\hline \multicolumn{6}{|l|}{ Graminées } \\
\hline Ray-grass & 13 & $\begin{array}{l}r=-0,890 \\
s=2,58\end{array}$ & & $\begin{array}{l}r=-0,906 \\
s=2,40\end{array}$ & $\begin{array}{l}r=-0,511 \\
s=9,31\end{array}$ \\
\hline Dactyle & 15 & $\begin{array}{l}r=-0,956 \\
s=2,82\end{array}$ & & $\begin{array}{l}r=-0,881 \\
s=4,57\end{array}$ & \\
\hline \multirow[t]{2}{*}{ Ensemble } & 28 & $\begin{array}{l}r=-0,945 \\
s=2,67\end{array}$ & & $\begin{array}{l}r=-0,875 \\
s=3,95\end{array}$ & \\
\hline & 16 & $\begin{array}{l}r=-0,925 \\
s=3.06\end{array}$ & & $\begin{array}{l}r=-0,839 \\
s=4,38\end{array}$ & $\begin{array}{l}r=-0,862 \\
s=4,09\end{array}$ \\
\hline \multicolumn{6}{|l|}{ Légumineuses } \\
\hline Fourrages verts & 22 & $\begin{array}{l}r=-0,914 \\
s=2,59\end{array}$ & $\begin{array}{l}r=0,921 \\
s=2,48\end{array}$ & $\begin{array}{l}r=-0,878 \\
s=3,05\end{array}$ & $\begin{array}{l}r=-0,860 \\
s=3,25\end{array}$ \\
\hline Foins & 15 & $\begin{array}{l}r=-0,899 \\
s=2,37\end{array}$ & $\begin{array}{l}r=0,806 \\
s=3,21\end{array}$ & $\begin{array}{l}r=-\cdots, 814 \\
s=3,15\end{array}$ & $\begin{array}{l}r=-0,905 \\
s=2,31\end{array}$ \\
\hline Ensemble & 37 & $\begin{array}{l}r=-0,938 \\
s=2,64\end{array}$ & $\begin{array}{l}r=0,740 \\
s=4,81\end{array}$ & $\begin{array}{l}r=-0,851 \\
s=3,76\end{array}$ & $\begin{array}{l}r=-0,890 \\
s=3,26\end{array}$ \\
\hline $\begin{array}{c}\text { Prairies naturelles } \\
\text { Herbe }\end{array}$ & 12 & $\begin{array}{l}r=-0,842 \\
s=3,26\end{array}$ & $\begin{array}{l}r=0,690 \\
s=4,38\end{array}$ & $\begin{array}{l}r=-0,816 \\
s=3,49\end{array}$ & $\begin{array}{l}r=-0,633 \\
s=4,68\end{array}$ \\
\hline Foins & 23 & $\begin{array}{l}r=-0,793 \\
s=2,68\end{array}$ & & $\begin{array}{l}r=-0,864 \\
s=2,22\end{array}$ & $\begin{array}{l}r=-0,872 \\
s=2,16\end{array}$ \\
\hline Ensemble & 35 & $\begin{array}{l}r=-0,892 \\
s=3,12\end{array}$ & & $\begin{array}{l}r=-0,813 \\
s=4,03\end{array}$ & $\begin{array}{l}r=-0,840 \\
s=3,75\end{array}$ \\
\hline Ensilages & 29 & $\begin{array}{l}r=-0,842 \\
s=3,63\end{array}$ & $\begin{array}{l}r=0,804 \\
s=4,00\end{array}$ & $\begin{array}{l}r=-0,555 \\
s=5,60\end{array}$ & $\begin{array}{l}r=-0,776 \\
s=4,24\end{array}$ \\
\hline Ensemble & 129 & $\begin{array}{l}r=-0,875 \\
s=3,84\end{array}$ & & $\begin{array}{l}r=-0,798 \\
s=4,73\end{array}$ & \\
\hline \multirow[b]{2}{*}{ Ensemble } & 78 & $\begin{array}{l}r=-0,793 \\
s=4,34\end{array}$ & $\begin{array}{l}r=0,754 \\
s=4,56\end{array}$ & $\begin{array}{l}r=-0,725 \\
s=4,78\end{array}$ & $\begin{array}{l}r=-0,825 \\
s=3,92\end{array}$ \\
\hline & 100 & $\begin{array}{l}r=-0,921 \\
s=3,22\end{array}$ & & $\begin{array}{l}r=-0,858 \\
s=6,14\end{array}$ & \\
\hline Fourrages verts + roins & 88 & $\begin{array}{l}r=-0,902 \\
s=3,35\end{array}$ & & $\begin{array}{l}r=-0,839 \\
s=4,14\end{array}$ & $\begin{array}{l}r=-0,860 \\
s=3,88\end{array}$ \\
\hline & 49 & $\begin{array}{l}r=-0,890 \\
s=3,35\end{array}$ & $\begin{array}{l}r=0,733 \\
s=4,80\end{array}$ & $\begin{array}{l}r=-0,819 \\
s=4,05\end{array}$ & $\begin{array}{l}r=-0,854 \\
s=3,67\end{array}$ \\
\hline
\end{tabular}




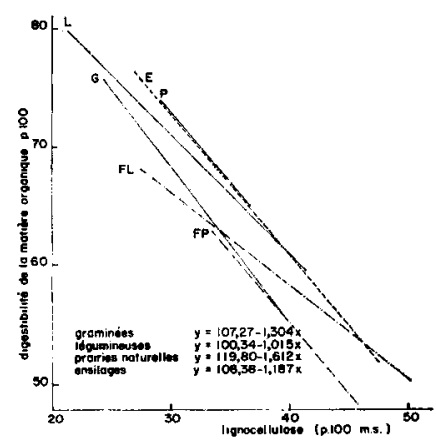

Fig. 7. - Relations entre la digestibilité de la matière organique el le résidu déminéralisé de la digestion cellulasique

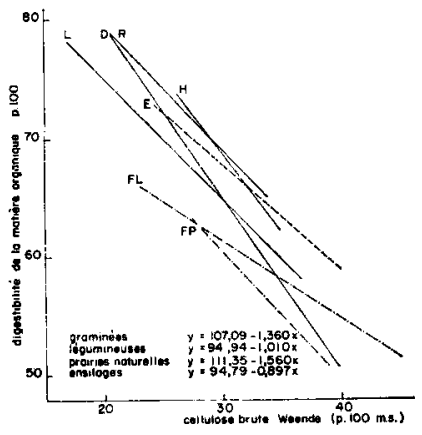

F1G. 9. - Relations entre la digestibilité de la matière organique et la lignocellulose

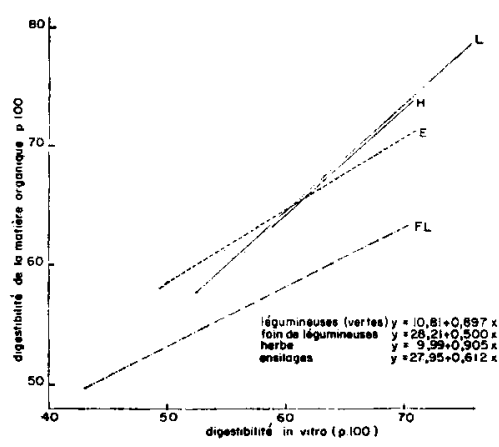

FIG. 8. - Relations entre la digestibilité de la matière organique et la cellulose brute Weende

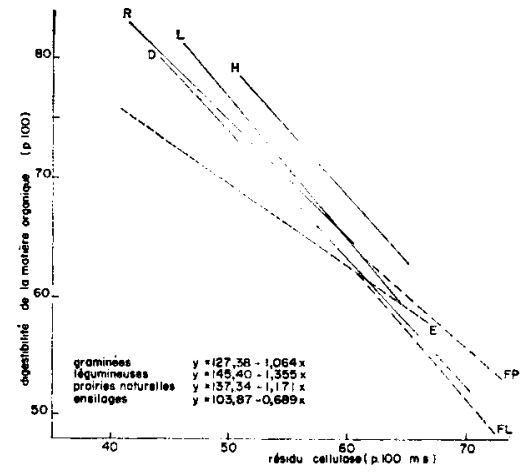

FIG. Io. - Relations entre la digestibilité de la matière organique et la digestibilité in vitro

$(\mathrm{R}=$ ray-grass $; \mathrm{D}=$ dactyle

$G=$ graminées ; $L=$ fourrages verts de légumineuses ;

$\mathrm{FL}=$ foins de légumineuses ; $\mathrm{H}=$ herbe de prairie naturelle ;

$\mathrm{FP}=$ foins de prairies naturelles ; $\mathrm{E}=$ ensilages) 
verts (séchés à l'étuve) de même digestibilité in vivo; en revanche, elle donne des valeurs très voisines, plus que la digestion cellulasique, pour les fourrages verts de légumineuses et pour ceux de prairies naturelles.

\section{Relations avec la quantité ingérée}

Les fourrages de légumineuses et de prairie naturelle et les ensilages ont été distribués ad libitum (ro p. Ioo de refus) aux 4 ou 6 moutons utilisés lors des mesures de digestibilité. Nous avons mis en relation avec les critères précédents les quantités ingérées ( $\mathrm{g}$ par $\mathrm{kg}^{0,75}$ ) de matière sèche (tabl. 5) et de matière organique digestible (tabl. 6).

La quantité de matière sèche ingérée présente une corrélation significative pratiquement avec tous les critères pour les différentes catégories de fourrages, à l'exception des foins de prairie naturelle. Les corrélations sont cependant toujours plus faibles que pour la digestibilité. Le critère permettant la meilleure prévision de la quantité ingérée varie selon la catégorie des fourrages ; c'est le résidu de la digestion cellulasique qui est le plus intéressant pour l'ensemble des 72 échantillons de fourrages verts et de foins $(r=-0,7$ ro).

Les corrélations sont plus élevées pour la quantité de matière organique digestible ingérée que pour la quantité de matière sèche et sont toutes hautement significatives à une exception près (tabl. 6). Le critère le plus intéressant varie avec la catégorie de fourrages. Pour l'ensemble des 72 échantillons de fourrages verts et de foins, c'est à nouveau la digestion cellulasique qui permet la meilleure prévision, qu'on l'exprime par la matière organique extraite $(r=0,825)$ ou par le résidu de la digestion $(r=0,8 \mathrm{I}$ ) $)$. La matière organique extraite par la solution tampon s'avère être presque aussi satisfaisante $(r=0,78 \mathrm{I})$.

\section{Reproductibilité}

Nous avons soumis à une analyse de variance les résultats des différents dosages effectués en triple sur 28 des derniers fourrages de l'étude précédente ( 15 herbes de prairie naturelle et $\mathrm{I} 3$ ensilages). L'écart-type est de $0, \mathrm{I} 6$ pour le résidu non déminéralisé de la digestion cellulasique, 0,22 pour le résidu déminéralisé, 0,21 pour la lignocellulose et 0,69 pour la digestibilité in vitro (bien que nous ayons éliminé dans ce dernier cas une des 3 valeurs pour 6 fourrages). Le résidu de la digestion cellulasique est donc dosé avec une précision comparable à la lignocellulose et beaucoup plus élevée que la digestibilité in vitro.

Pour mesurer la reproductibilité entre séries de la digestion cellulasique, celle-ci a été conduite en triple une fois par semaine, pendant 5 semaines consécutives, sur 5 fourrages qui différaient par leur origine botanique et leur digestibilité. L'analyse de la variance (tabl. 7) ne révèle pas de différence significative entre séries ; au contraire, les différences entre séries sont hautement significatives pour la digestibilité in vitro des deux fourrages utilisés comme indicateurs (en triple) dans les 5 séries de mesures hebdomadaires correspondantes. La digestion cellulasique est donc plus reproductible que la digestibilité in vitro, que ce soit intra séries ou entre séries. La variabilité que nous observons pour la digestibilité in vitro est tout à fait comparable à celle qui a été rapportée par ses promoteurs, TH,LEY et TERRY (écarts-types de 


\begin{tabular}{|c|c|c|c|c|c|c|c|c|}
\hline 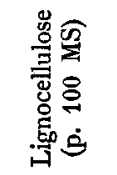 & 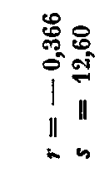 & 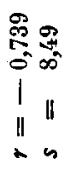 & 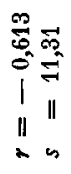 & 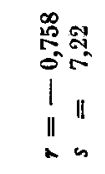 & $\tilde{z}$ & 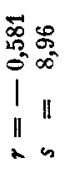 & 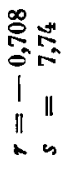 & 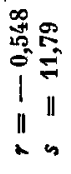 \\
\hline 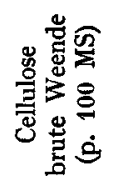 & 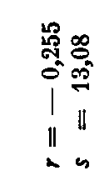 & 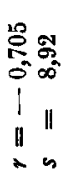 & 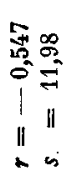 & 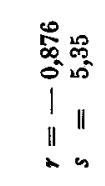 & $\frac{n}{z}$ & 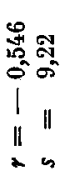 & 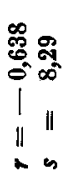 & 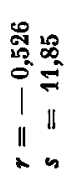 \\
\hline 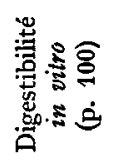 & 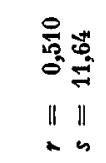 & 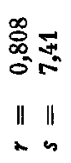 & 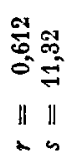 & 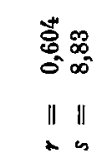 & & & 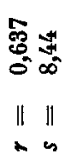 & \\
\hline 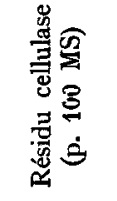 & 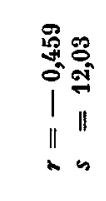 & 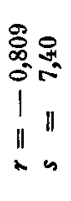 & 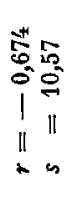 & 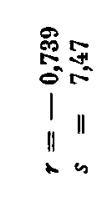 & $\check{z}$ & 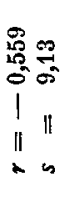 & 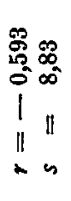 & 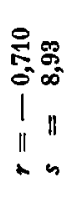 \\
\hline 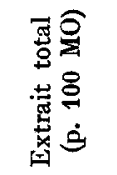 & 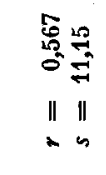 & $\begin{array}{l}5 \\
58 \\
0 \\
0 \\
\| 11 \\
+4\end{array}$ & 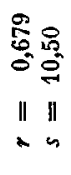 & 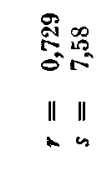 & $\underset{Z}{\mathscr{Z}}$ & 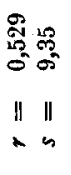 & 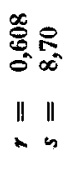 & 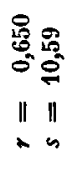 \\
\hline 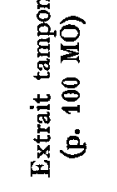 & 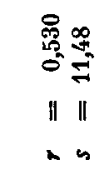 & 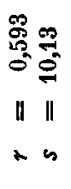 & 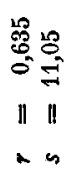 & 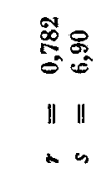 & $\mathscr{Z}$ & 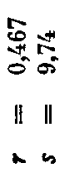 & 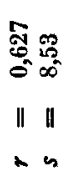 & 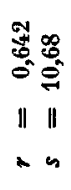 \\
\hline 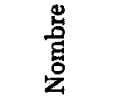 & สี & $\stackrel{20}{\rightarrow}$ & 正 & $\stackrel{N}{\sim}$ & 路 & 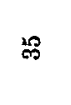 & I্ & ฉ \\
\hline & 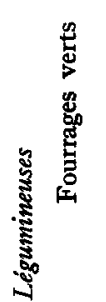 & 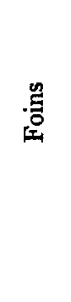 & 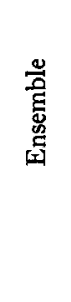 & 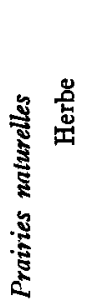 & 营 & 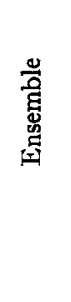 & 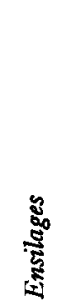 & 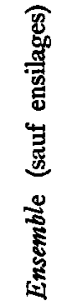 \\
\hline
\end{tabular}

Annales de Biologie animale. - I969. 
(⿸丆口

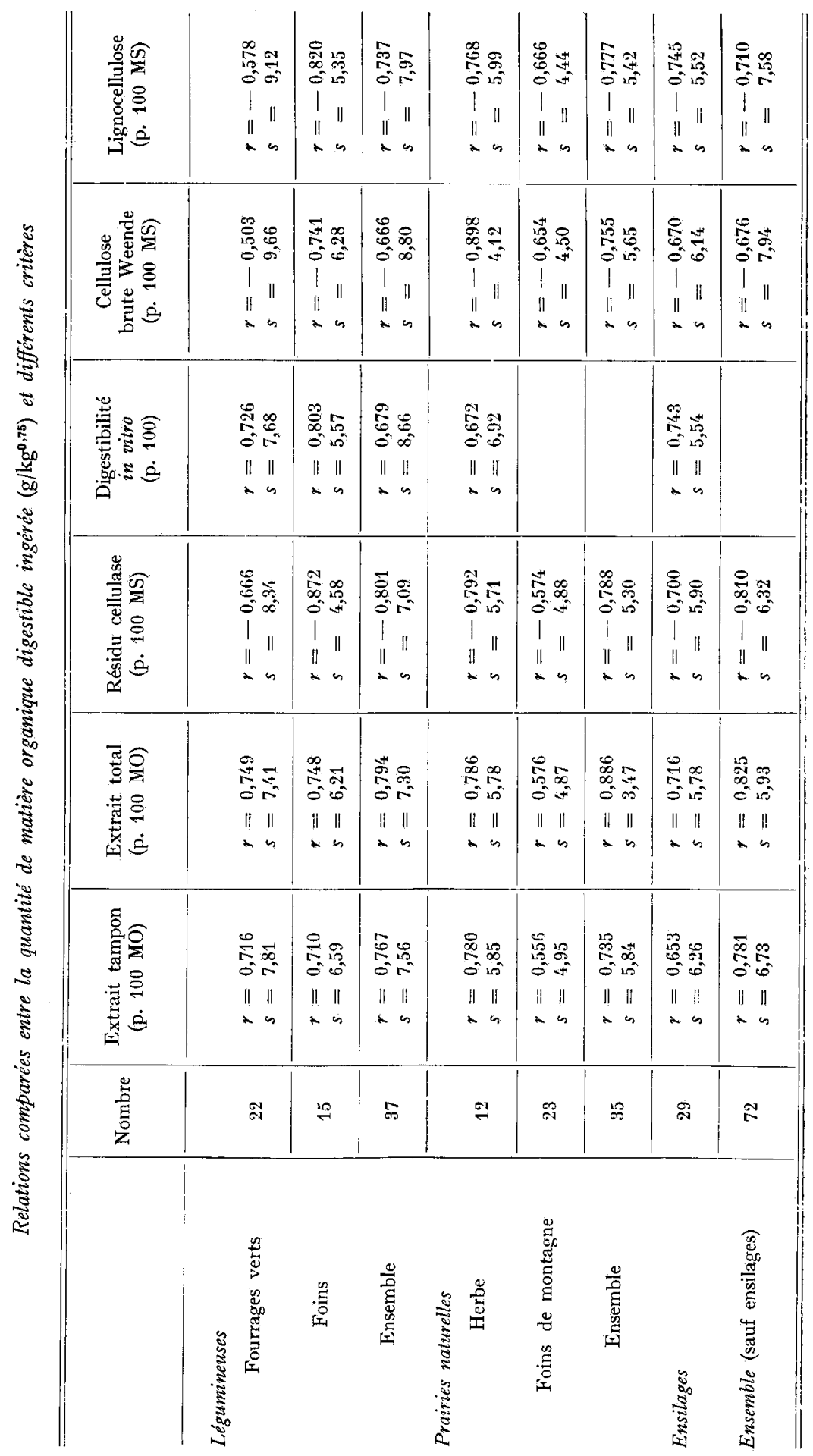


0,66 intra séries et $\mathrm{I}, \mathrm{I} 8$ entre essais). Elle est en revanche beaucoup plus faible que celle qui a été mesurée dans les études américaines (BOWDEN et CHURCH, I962; BAumgardT et Hi Kon OH, I964; BARNES, I967).

Il est à noter que, dans nos essais, la solution cellulasique a été préparée chaque semaine à partir de la même poudre. Il n'est pas exclu que l'activité puisse varier d'un lot de poudre à l'autre.

\section{TABLEAU 7}

Reproductibilité comparée entre essais et intra essais de la digestion cellulasique ( 5 fourrages)

et de la digestibilité in vitro (2 fourrages)

\begin{tabular}{|c|c|c|c|c|c|c|}
\hline \multirow[b]{2}{*}{ Origine de la variation } & \multicolumn{3}{|c|}{ - Résidu cellulase brut } & \multicolumn{3}{|c|}{ Digestibilité in vitro } \\
\hline & $\begin{array}{c}\text { Somme } \\
\text { des carrés }\end{array}$ & $\begin{array}{c}\text { Degrés } \\
\text { de liberté }\end{array}$ & Variance & $\begin{array}{c}\text { Somme } \\
\text { des carrés }\end{array}$ & $\begin{array}{l}\text { Degrés } \\
\text { de liberté }\end{array}$ & Variance \\
\hline $\begin{array}{l}\text { Entre fourrages } \ldots \ldots \ldots \ldots \ldots \ldots \\
\text { Entre semaines } \ldots \ldots \ldots \ldots \ldots \ldots \\
\text { Résiduelle............... }\end{array}$ & $\begin{array}{r}832,84 \\
1,00 \\
8,92\end{array}$ & $\begin{array}{r}4 \\
4 \\
66\end{array}$ & $\begin{array}{c}208,21^{* *} \\
0,25 \\
0,14\end{array}$ & $\begin{array}{r}324,46 \\
13,43 \\
9,90\end{array}$ & $\begin{array}{r}1 \\
4 \\
24\end{array}$ & $\begin{array}{c}324,46^{* *} \\
3,36^{* *} \\
0,41\end{array}$ \\
\hline Total ................. & 842,76 & 74 & 11,39 & 347,79 & 29 & 11,99 \\
\hline
\end{tabular}

** Différence hautement significative.

\section{DISCUSSION}

La préparation cellulasique que nous avons utilisée doit contenir non seulement des cellulases, mais aussi des enzymes qui attaquent les hémicelluloses et les protéines. Par électrophorèse sur gel d'amidon, LE GRAND et THIVFND (I967) ont effectivement constaté qu'elle contenait un grand nombre de protéines, dont deux avaient d'ailleurs une action amylolytique; par chromatographie sur gel de dextrane du type Sephadex, ils ont mis en évidence au moins trois fractions cellulolytiques : une agissant seulement sur la cellulose insoluble (linters de cotons) et les deux autres seulement sur la cellulose soluble (carboxy-méthylcellulose). D'ailleurs, les préparations cellulasiques fongiques les mieux connues, telles que celle de Myrothecium verrucaria, sont elles aussi très hétérogènes (cf. WhitakeR, I963; HASHIMoto et Nisizawa, Ig63).

Le fait que notre préparation cellulasique contienne les enzymes attaquant les hémicelluloses est avantageux pour 1'objectif poursuivi ; nous cherchons en effet à obtenir une digestion des membranes du fourrage semblable à celle qui est effectuée par la population microbienne dans le rumen. Et c'est bien ce que nous obtenons (fig. 3), tout au moins lorsque nous considérons un ensemble d'échantillons dont la digestibilité varie dans des limites très importantes, de 50 à plus de 80 p. Ioo; l'importance de la dégradation par la cellulase de la lignocellulose ou des polysaccharides 
membranaires est en corrélation positive avec le coefficient de digestibilité de ces fractions ; elle varie en sens inverse du degré de lignification comme varie celle de la digestibilité des membranes in vivo (cf. discussion de JARrige et Minson, I964); enfin, la cellulose des légumineuses est plus résistante à l'attaque de la cellulase que celle des graminées de digestibilité comparable, de même qu'elle est moins digestible in vivo. Cette différence entre légumineuses et graminées est cependant beaucoup plus importante qu' in vivo et elle persiste pour les lignocelluloses isolées (fig. 2), bien que les proportions solubilisées par la cellulase soient alors plus élevées par suite de l'hydrolyse sulfurique préalable. Elle traduit des différences entre les deux familles dans la structure des membranes et dans la constitution de la cellulose, mais elle est probablement accrue par la composition de la préparation cellulasique S. E. A. B. que nous avons utilisée. Quoi qu'il en soit, celle-ci solubilise moins de matière sèche dans les légumineuses que dans les graminées, à l'inverse de la cellulase 36 fournie par Roнm et HAAs qui est beaucoup plus active sur les échantillons de luzerne et de trèfle violet que sur ceux de fléole et de brome de digestibilité comparable (DONEFER et al. I963).

La digestion cellulasique extrait du fourrage deux catégories de constituants qui, chacune, présentent une relation positive significative avec le coefficient de digestibilité du fourrage ou avec sa teneur en matière organique digestible; d'une part, les constituants solubles (sucres, fructosanes, constituants azotés non protéiques, acides organiques, ...) qui sont extraits par la solution tampon faiblement acide; d'autre part, la fraction des polysaccharides membranaires et des protéines (et aussi peut-être d'autres constituants) qui est solubilisée par la préparation cellulasique elle-même. La somme de ces deux extraits (ou le résidu du traitement) présente une liaison encore plus étroite avec la digestibilité ; d'abord pour chacune des catégories de fourrages, essentiellement parce que l'amplitude de variation est accrue ; et aussi pour l'ensemble des fourrages d'origine botanique différente, grâce à d'heureuses compensations qu'illustre la comparaison des figures 4,5 et 6 : ainsi, la solution tampon extrait plus de constituants dans la luzerne que dans les graminées de digestibilité comparable, mais la cellulase en extrait moins. De même, les coefficients de régression sont du même ordre pour les différentes catégories d'échantillons, à l'exception des ensilages qui doivent donc être traités séparément.

Pour prévoir au mieux la digestibilité à partir de la digestion cellulasique, il faudra d'ailleurs utiliser des relations par catégorie de fourrages, relations établies à partir d'un plus grand nombre d'échantillons. I1 en sera ainsi notamment pour comparer entre elles les espèces d'une même famille : nous observons par exemple que la droite de régression entre la digestibilité et le résidu de la digestions cellulasique pour le ray-grass d'Italie est décalée par rapport à celles obtenues pour le ray-grass anglais, le dactyle et la fétuque élevée :

$$
\begin{array}{ll}
\text { Ray-grass anglais }(\mathrm{I} 3) \ldots \ldots \ldots \ldots \ldots & y=\mathrm{I} 23,2-0,973 x( \pm 2,58) \\
\text { Ray-grass d'Italie }(\mathrm{I} 7) \ldots \ldots \ldots \ldots . & y=\mathrm{I} 2 \mathrm{I}, 5-\mathrm{I}, 05 \mathrm{I} x( \pm \mathrm{I}, 58) \\
\text { Dactyle }(\mathrm{I} 5) \ldots \ldots \ldots \ldots \ldots \ldots \ldots & y=\mathrm{I} 27,0-\mathrm{I}, 066 x( \pm 2,82) \\
\text { Fétuque élevée }(\mathrm{I} 4) \ldots \ldots \ldots \ldots \ldots & y=\mathrm{I} 20, \mathrm{I}-0,907 x( \pm \mathrm{I}, 59)
\end{array}
$$

Cela résulte du fait que le ray-grass d'Italie est plus riche en glucides solubles que les trois autres graminées, à digestibilité égale ; 1'extrait par la solution tampon 
en est accru et le résidu de la digestion cellulasique diminue d'autant ; 1'extrait par la cellulase est en revanche très semblable pour les 4 espèces.

D'une façon générale, la digestion cellulasique permet de prévoir la digestibilité du fourrage avec une précision satisfaisante. Mis à part les ensilages, l'erreur d'estimation appréciée par l'écart-type réduit, est inférieure à 3 points pour les différentes catégories de fourrages ; elle est en moyenne de 2,82 pour l'estimation de la matière organique digestible des roo échantillons de fourrages verts et de foins. La digestion cellulasique paraît être, à ce point de vue, plutôt supérieure aux trois autres méthodes auxquelles nous 1'avons comparée, à la cellulose brute Weende plus particulièrement. Elle doit leur être aussi comparée sur le plan de la reproductibilité, de la rapidité et de l'adaptation à la série. Ellle a une reproductibilité du même ordre que la détermination de la cellulose brute et de la lignocellulose et qui pourra sans doute être améliorée, notamment par une filtration plus efficace. C'est là son avantage majeur par rapport aux techniques de digestibilité in vitro : 1'activité du liquide du rumen qu'utilisent celles-ci peut en effet varier de façon importante d'une semaine à l'autre, si standardisé que soit le régime de l'animal donneur ; elle varie à plus forte raison d'un laboratoire à l'autre et il vient s'y ajouter des différences dans les techniques : ainsi la digestibilité in vitro moyenne de 3 échantillons a varié de 38,7 à 53,3 p. roo pour cinq laboratoires américains dans l'enquête effectuée par BARNES (I967). La digestion cellulasique ne comportant qu'un seul traitement est plus simple que le dosage de la cellulose brute qui en comporte deux, et aussi que la digestibilité in vitro, suivant la technique de TIL,EY et TERRY, qui implique, en plus, l'entretien d'animaux porteurs de fistule du rumen. Elle est cependant moins rapide que le dosage de la lignocellulose de VAN SoEst qui s'effectue en une seule opération de courte durée.

La digestion cellulasique offre donc un moyen simple et facile à adapter à la série, pour estimer la valeur nutritive des fourrages. Elle est nettement moins satisfaisante pour prévoir " l'acceptabilité " du fourrage, tout en l'étant plutôt plus que les trois autres méthodes examinées. On peut espérer améliorer la relation avec la quantité ingérée en lui associant d'autres critères.

Reçu pour publication en décembre 1968.

\section{REMERCIEMENTS}

Nous remercions la Société d'Études et d'Application Biochimiques de nous avoir fourni la préparation cellulasique utilisée dans cette étude.

\section{SUMMARY}

EFFECT OF A FUNGAL CELLULASE ON FORAGES AND ITS VALUE

FOR PREDICTING DIGESTIBILITY

The effect of a fungal cellulase on forages of widely different botanical composition and digestibility in vivo was studied to see whether it would allow prediction of the digestibility of these forages. 
I. The methods of digestion are first described. It was done at $\mathrm{pH} 4.6$ and lasted for $24 \mathrm{~h}$ since the amount dissolved increased only slowly after that (fig. 1 ).

2. The cellulase hydrolyzed a fraction of the cellulose and hemicelluloses completely (tabl. I). It also attacked the proteins to about 20 per cent. Thus, it was a mixture of enzymes.

3. The degree of breakdown of lignocellulose (fig. 2) and the membrane polysaccharides, cellulose plus hemicelluloses (fig. 3), was positively correlated with the digestibility of these fractions in the digestive tract of ruminants and negatively correlated with lignin content. It was greater for grasses than for legumes of similar digestibility.

4. The amounts of the substances extracted by the buffer solution, by cellulase digestion (buffer solution plus cellulase) and by cellulase (the difference between those two amounts) were all three closely correlated with digestibility of the forage (table 3 ; fig. 4 to 6 ) and with the intake of digestible organic matter by the sheep (table 6). It was evidently the same for the residue after cellulase digestion (table 3). This was shown with roo samples of green forage and hay, representative of the main categories of forage, and with 29 samples of silage.

5. Cellulase digestion allowed prediction of digestibility and of intake with an error generally less than with crude cellulose, acid detergent fiber (VAN SOEST, 1963) or digestibility in vitro (TILLEY and TERry, 1963) (tables 4, 5 and 6 ; fig. 7 to I0). Its advantage is greater for digestibility than for intake.

6. Cellulase digestion is as reproductible as acid detergent fiber and more than digestibility in vitro (table 7 ).

\section{RÉFÉRENCES BIBLIOGRAPHIQUES}

BaumgardT B. R., HI KoN OH., 1964. Evaluation of forages in the laboratory. IV. Within and among trial variability of the Wisconsin artificial rumen procedure. J. Dairy Sci., 47, 263-266.

Barnes R. F., 1967. Collaborative in vitro rumen fermentation studies on forage substrates. J. Anim. Sci., 26, II 20-II30.

BowDEN D. M., CHURCH D. C., I962. Artificial rumen investigations. I. Variability of dry matter and cellulose digestibility and production of volatile fatty acids. J. Dairy Sci., 45, 972-979.

Donefer E., Niemann P. J., Crampton E. W., Lloyd L. E., 1963. Dry matter disappearance by enzyme and aqueous solutions to predict the nutritive value of forages. J. Dairy Sci., 46, 965-970.

Hashimoto Y., Nisizawa K., 1963. Purification of cellulase and related enzymes. in E. T. ReEse : Advances in enzymic hydrolysis of cellulose and related materials. Pergamon Press Ed.

JARRIGE R., 195r. Analyse des constituants glucidiques des plantes fourragères. I. Fractionnement des membranes par les hydrolyses acides. Ann. Biol. anim. Bioch. Biophys., 1, 163-212.

Jarrige R., Minson D., 1964. Digestibilité des constituants du ray-grass anglais $\mathrm{S}_{24}$ et du dactyle $\mathrm{S} 33$, plus spécialement des constituants glucidiques. Ann. Zootech., 18, I I 7-I 50.

LE Grand Y., Thivend P., 1967. Étude de la dégradation enzymatique de la cellulose : fractionnement sur gel de dextranes d'une poudre cellulolytique d'origine fongique. Int. Biodetn. Bull., 3, 67-76.

Johnson R. R., 1966. Techniques and procedures for in vitro and in vivo rumen studies. J. Anim. Sci., $25,855^{-8} 75$.

Tilley J. M. A., Terry R. A., 1963. A two stage technique for in vitro digestion of forage crops. J. Brit. Grassl. Soc., 18, I04-1 I I.

VAN Soest P. J., 1963. Use of detergents in the analysis of fibrous feeds. II. A rapid method of the determination of fiber and lignin. J. Ass. Off. Agr. Chem., 46, 829-835.

WhitAKER D. R., I963. Criteria for characterizing cellulase, in E. T. ReESE : Advances in enzymic hydrolysis of cellulose and related materials. Pergamon Press Ed. 